\title{
Endoscopic submucosal dissection for rectal neoplasia extending to the dentate line: European experience
}

\section{(1) $\odot \ominus$}

\author{
Authors \\ Andreas Probst ${ }^{1}$, Alanna Ebigbo ${ }^{1}$, Bruno Märkl², Saskia Ting ${ }^{2}$, Tina Schaller ${ }^{2}$, Matthias Anthuber ${ }^{3}$, Carola \\ Fleischmann', Helmut Messmann'
}

Institutions

1 Department of Gastroenterology, Klinikum Augsburg, Germany

2 Institute of Pathology, Klinikum Augsburg, Germany

3 Department of General, Visceral and Transplantation Surgery, Klinikum Augsburg, Germany

submitted 15.5.2018

accepted after revision 5.9.2018

\author{
Bibliography \\ DOI https://doi.org/10.1055/a-0749-8735 | \\ Endoscopy International Open 2018; 06: E1355-E1362 \\ (c) Georg Thieme Verlag KG Stuttgart · New York \\ ISSN 2364-3722
}

\section{Corresponding author}

Andreas Probst, MD, III. Medizinische Klinik, Klinikum Augsburg, Stenglinstrasse 2, 86156 Augsburg, Germany Fax: +49-821-400-3331

andreas.probst@klinikum-augsburg.de

\section{ABSTRACT}

Background and study aims The ideal treatment strategy for rectal neoplasia extending to the dentate line (RNDL) is not well defined. Endoscopic mucosal resection
(EMR) and submucosal dissection (ESD) compete with surgical techniques such as transanal endoscopic microsurgery (TEM). Non-Asian data and prospective data on ESD are lacking. The study aim was to evaluate the role of ESD in treatment of RNDL in a Western center.

Patients and methods Eighty-six patients with rectal adenomas were included. ESD was performed in 86 rectal adenomas including 24 RNDLs (27.9\%) and 62 lesions distant from the dentate line (72.1\%).

Results En bloc resection rate was comparable (91.7\% vs. 93.5\%, $P=0.670$ ) between ESD for RNDL and non-RNDL. R0 resection rate was significantly lower in ESD for RNDL compared to that for non-RNDL (70.8\% vs $88.7 \%$; $P=$ 0.039 ), but most non-R0 resection was unclear margin $(\mathrm{Rx})$ and was not obvious positive margin (R1). Accordingly, the recurrence rate after ESD for RNDL (4.5\%) was not statistically different from that for non-RNDL $(0 \%, P=0.275)$ and was lower than that previously reported for EMR. Median procedure time was 127 vs. 110 minutes $(P=0.182)$. Risk of delayed bleeding ( $20.8 \%$ vs. $0 \%, P=0.001)$ and postinterventional pain $(33.3 \%$ vs. $14.5 \%, P=0.07)$ increased in RNDL cases, but they were managed conservatively. Incidence of stricture $(4.2 \%$ vs. $1.6 \%, P=0.483)$ and perforation ( $0 \%$ vs. $1.6 \%, P=1.000)$ were similar.

Conclusions ESD is a feasible and safe resection technique for RNDLs. A randomized controlled trial comparing ESD to other methods (EMR or transanal surgery) is warranted.

\section{Introduction}

Today, endoscopic mucosal resection (EMR) is a well-established and widely accepted resection technique for colorectal adenomas [1]. The major disadvantage is an increased risk of recurrence when endoscopic resection (ER) has to be performed piecemeal in lesions exceeding $20 \mathrm{~mm}$ in diameter. Endoscopic submucosal dissection (ESD) allows en bloc resection regardless of a lesion's size, leading to a minimized recurrence risk [2]. However, ESD is technically difficult, time-consuming and there is a learning curve especially for western endoscopists [3-4]. Western data on colorectal ESD are limited and the role of ESD for colorectal lesions is, at present, not well defined.

When rectal neoplasia extends to the dentate line (RNDL), ER involves specific difficulties. In comparison to the proximal rectum and the colon, risk for bleeding and pain may be higher due to presence of rectal venous plexus and sensory nerves in the squamous epithelium of the anal canal. Furthermore, direct drainage into the systemic circulation can increase risk of bacteremia. Beyond these anatomical characteristics, the narrow lumen and vicinity of the anal sphincter increase the technical difficulties including poor maneuverability and reduced visualization of the resection field. Today, data on ER in RNDL are limited and current guidelines give no specific recommendations 
on the ideal treatment strategy (EMR, ESD, transanal surgery) [5-6].

The aim of this study was to analyze the efficacy and safety of ESD in RNDLs in a European center beyond the learning curve.

\section{Patients and methods}

The study was conducted as a single-center uncontrolled study in a German referral center (Department of Gastroenterology, Klinikum Augsburg, Germany). Patients were included in the German ESD registry which was approved by the ethics committee of the Ludwig-Maximilians-University Munich, Germany. Data were collected prospectively within this registry and analyzed retrospectively. At the beginning of the study, ESD was standard treatment for rectal neoplasia in our department as reported previously [7]. Patients were included from June 2016 to February 2018.

\section{Inclusion criteria for ESD}

- Endoscopic diagnosis of rectal neoplasia $(0-15 \mathrm{~cm}$ from the anal verge)

- Lesions diameter $\geq 20 \mathrm{~mm}$

- Age $\geq 18$ years

- American Society of Anesthesiologists (ASA) Score I-III

- Written informed consent to participate in the German ESD registry

- Written informed consent for the ESD procedure after patients received detailed information about ESD and alternative treatment options (EMR, transanal surgery).

\section{Exclusion criteria for ESD}

- Suspected invasion into or beyond the deep submucosal layer after diagnostic workup ( $\geq \mathrm{T} 1 \mathrm{sm} 3$ carcinoma)

- Biopsies showing submucosal invasive cancer

- Circumferential lesions

- Pretreated lesions with complete non-lifting

- Submucosal lesions

- Concomitant malignant disease without curative treatment option

\section{Secondary exclusion after ESD}

- Histopathological diagnosis of submucosal invasive cancer (SMIC)

\section{Outcome criteria}

Measured outcome parameters were procedural success (R0 resection rate, recurrence rate) and safety (complications).

\section{Diagnostic workup}

Video endoscopy with white light (WLE) and narrow band imaging (NBI) was performed with a videogastroscope (GIFHQ190; Olympus Medical Systems, Tokyo, Japan).

Lesions were classified according to the Paris classification and the classification of laterally spreading tumors (LST) [89]. When SMIC was suspected by morphological criteria (Paris type 0-Is, 0-Is-IIc, 0-Ila-Is, 0-Ila-Ilc and/or nongranular type le- sions with depressed morphology), biopsies were taken and endoscopic ultrasound (EUS) was performed to rule out advanced cancer (>T1) and LNM. When cancer was confirmed in a biopsy, staging was completed with additional magnetic resonance imaging of the rectum and computed tomography scan of the chest and abdomen. After the diagnostic workup, ESD was performed. When submucosal invasive cancer was shown in biopsies or advanced cancer (>T1) was suspected, ER was not performed and surgical resection was recommended. In lesions appearing benign by macroscopic criteria, EUS was not performed and biopsies were not taken prior to ER.

\section{ESD procedure and follow-up}

A videogastroscope (GIF-HQ190, Olympus Medical Systems, Tokyo, Japan) with a transparent cap (D-201-11804, Olympus) at the tip of the scope and insufflation with carbon dioxide was used for ESD. The standard solution for submucosal injection was a mixture of saline, epinephrine (1:100.000), glycerol (10\%), and a slight amount of indigo-carmine. Local anesthetics were not used for injection. During and after completed ESD, large visible vessels or bleeding sites were coagulated with the Coagrasper (FD-410 LR, Olympus). Antibiotics were administered individually depending on the endoscopist's decision. A VIO 300 D electrosurgical generator (ERBE Elektromedizin, Tübingen, Germany) was used (endo cut I mode 60-80 W for cutting and spray coag mode $60 \mathrm{~W}$ for coagulation). Mucosal incision and submucosal dissection were performed with the hookknife (KD-620LR; Olympus).

ESD was performed in a standardized way starting with injection, mucosal incision, and submucosal dissection at the lesion's distal margin (forward view). Afterward, mucosal incision was completed circumferentially (retroflexed view) and submucosal dissection was completed in forward and retroflexed position. In lesions exceeding $30 \%$ to $40 \%$ of the circumference, a submucosal tunnel was created in the middle of the resection area after circumferential incision and dissection was completed towards the lateral margins afterwards. An ESD procedure is shown in > Fig. 1. Sedation with midazolam, pethidine and propofol was administered by a second physician, under continuous cardiorespiratory monitoring. Patients stayed in the hospital for 48 to 96 hours after ESD. Routine control endoscopies were not performed. An equal number of ESD procedures were performed by three endoscopists experienced in rectal ESD (A.P., A. E., H. M.). Each endoscopist had performed 50 to 200 rectal ESDs prior to the study. Anticoagulants except aspirin had been stopped before ESD and were restarted 5 to 7 days after the procedure depending on the endoscopist's decision.

During the hospital stay, the patient's body temperature was taken twice daily. When it exceeded $38^{\circ} \mathrm{C}$, antibiotics were started intravenously (ceftriaxone $2 \mathrm{~g}$ once daily and metronidazole $0.5 \mathrm{~g}$ every 8 hours). Patients were questioned three times a day about postinterventional pain, and analgetics were offered on demand at any time (metamizole, acetaminophen).

When SMIC was diagnosed in the specimen, the further treatment strategy (follow-up versus surgery) was discussed in an interdisciplinary board of gastroenterologists and surgeons. 


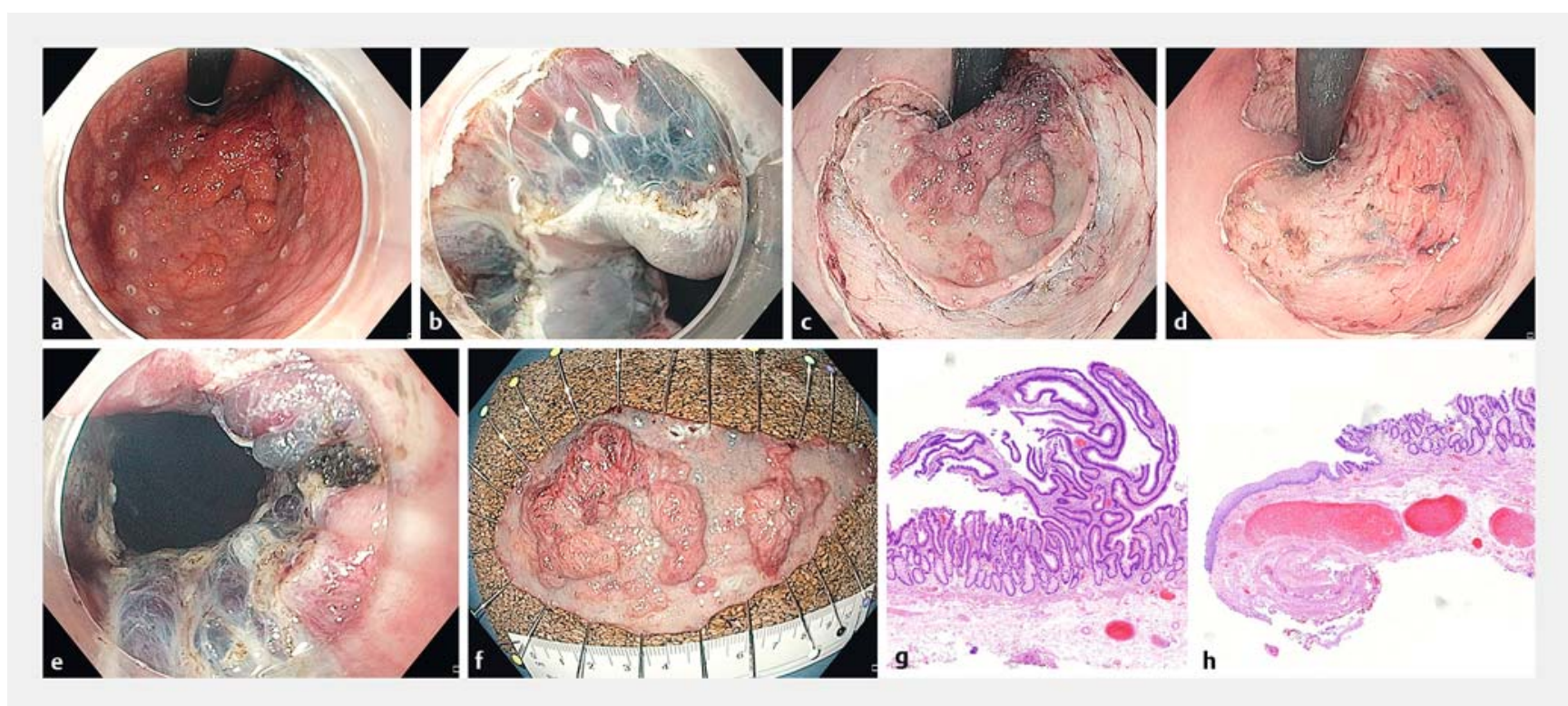

- Fig. 1 ESD of a granular-type LST extending to the dentate line (Paris type 0 -Ila + Is). a Retroflexed view after marking the resection borders using hook-knife. $\mathbf{b}$ Mucosal incision of the squamous epithelium in the anal canal (forward view). c Retroflexed view after completion of the mucosal incision. $\mathbf{d}$ Retroflexed view after completion of ESD. e Distal resection margin including hemorrhoids after completion of ESD (forward view). f Resection specimen (diameter $115 \times 50 \mathrm{~mm}$; area $45.1 \mathrm{~cm}^{2}$ ). $\mathbf{g}$ Histopathologic assessment showing adenoma with focal HGIEN resected R0 (H\&E, scanning magnification). h Distal resection margin showing R0 resection within the squamous epithelium and thick vessels resected from the rectal venous plexus (H\&E, scanning magnification).

Follow-up endoscopy was performed 4 to 6 months after ESD with a videogastroscope (GIF-HQ190, Olympus Medical Systems, Tokyo, Japan) with a transparent cap using WLE and NBI. Biopsies were taken when residual neoplasia was suspected. When recurrence was diagnosed, endoscopic retreatment was performed and another follow-up endoscopy was scheduled 3 months later. When recurrence was ruled out, follow-up endoscopy was scheduled 1 year later. Follow-up recommendation was given according to a local protocol.

\section{Histopathologic workup}

ESD specimens were fixed on cork with needles. Specimen size was measured and specimens were sent for histopathological assessment. The specimens were cut into parallel sections of 3-mm thickness or less and completely embedded in paraffin in an oriented fashion. Intramucosal lesions were classified as adenoma with low-grade or high-grade intraepithelial neoplasia (LGIEN, HGIEN). R0 or R1 was described for the vertical margin (VM) and the horizontal margin (HM).

\section{Complications}

Complications were defined as bleeding, perforation, stenosis or death. Bleeding during ESD was considered as a complication when it was severe, leading to premature termination of ER. Delayed bleeding was defined as when clinical bleeding signs were observed after ESD (rectal bleeding or hemoglobin drop $>2 \mathrm{~g} / \mathrm{L}$ ) [10]. In these cases, endoscopic treatment was performed. Perforation was defined as an obvious endoscopic view into the perirectal space or the peritoneal cavity. Stenosis was considered as a complication when it was symptomatic.
Complications were classified according to the Common Terminology Criteria for Adverse Events (CTCAE) Version 4.0.

\section{Statistical analysis}

Depending on the number of groups, a Mann-Whitney Rank Sum test or a Kruskal-Wallis One Way Analysis of Variance on Ranks was used to compare numeric values. For the comparison of categorical data, a Chi Square or Fisher Exact test was employed, depending on the expected frequency of the observations. $P$ values $<0.05$ were considered statistically significant. Calculations were performed using the software package Sigma Plot 13.0 (Systat Software, San Jose, California, United States).

\section{Results}

\section{Patient and lesion characteristics}

Over a 17-month-period, 112 patients referred for ER of rectal neoplasia were enrolled ( $60 \%$ men; median age $64.0 \mathrm{y}$, range 36-86 y). After exclusion of 11 patients (9.8\%), ESD was performed in 101 patients (90.2\%). P Fig. 2 gives an overview of the study population. Histopathology revealed SMIC in 15 of the resected lesions (14.9\%). Nine of them underwent additional surgery ( 6 patients with deep invasion making completion of en bloc resection impossible and leading to piecemeal resection and another 3 patients with R0 resection but submucosal invasion exceeding $1000 \mu \mathrm{m}$ in the ESD specimen). Surgical specimens showed one pT2pN0 and another pT2pN1 cancer while seven specimens did not show residual cancer or lymph node metastasis. Six patients underwent follow-up after ESD 
Neoplastic rectal lesions referred for ESD $n=112$

Excluded prior to resection (referred for surgical resection) $\mathbf{n}=\mathbf{1 1}$

- Advanced malignancy suspected $\mathrm{n}=6$ (surgery $n=5$ : pT1 high-risk $n=1$, pT3 $n=2$, HGIEN $n=2$, treatment refused $n=1$ )

- Circumferential lesion $\mathrm{n}=2$ (surgery $n=2$ : HGIEN $n=2$ )

- Non-lifting scar after repeated pretreatment $n=3$ (surgery refused $n=3$ : treatment with EMR and APC)

Lesions treated with $\mathrm{ESD} n=101$

$\begin{aligned} & \text { Benign lesion } \mathbf{n}=86 \\ & \text { - Adenoma with LGIEN } \\ & \mathrm{n}=29\end{aligned}$
$\begin{aligned} & \text { Adenoma with HGIEN } \\ & \mathrm{n}=57\end{aligned}$
$\begin{aligned} & \text { cancer } \mathbf{n}=\mathbf{1 5} \\ & \text { - Low-risk criteria } \mathrm{n}=6\end{aligned}$
$\begin{aligned} & \text { - High-risk criteria } \mathrm{n}=9 \\ & \text { Extending to the dentate } \\ & \text { line } \mathrm{n}=24\end{aligned}$

- Fig. 2 Overview of the study population.

of pT1 cancers with submucosal invasion $\leq 1000 \mu \mathrm{m}$ and did not show recurrence during follow-up. None of the SMICs had extended to the dentate line. To make the groups comparable for follow-up and especially regarding recurrences, SMICs were excluded from further analysis.

Eighty-six benign lesions were included for further analysis. Twenty-four lesions extended to the dentate line (27.9\%) while 62 lesions did not reach the squamous epithelium of the anal canal $(72.1 \%)$. Female sex was higher in the RNDL group (54.2\% versus $32.3 \% ; P=0.104$ ). Both groups were comparable regarding patient age, ASA status, lesion size, lesion morphology and proportion of pretreated lesions. Paris type $0-1 l a+$ Is (granular type LST with nodules) was the most frequent lesion type (73.3\%). Fourteen of 24 lesions (58.3\%) involving the dentate line were located on hemorrhoids. Lesion size was calculated as the surface of an ellipse by using the long and the short diameter of the resection specimen; using only the largest diameter would not describe lesion size correctly, especially in RNDLs lesions which have an oval shape in most cases ( $\bullet$ Fig. 1f). Patient and lesion characteristics are shown in $\triangleright$ Table 1.

\section{Procedure characteristics}

- Table 2 shows procedure characteristics. Median procedure time was 119 minutes and median resection speed was 6.9 minutes $/ \mathrm{cm}^{2}$. Both parameters did not differ significantly between RNDL lesions and proximal lesions. The en bloc resection rate was comparable ( $91.7 \%$ versus $93.5 \% ; P=0.670$ ) while the R0 resection rate was significantly lower after ESD for RNDLs ( $70.8 \%$ versus $88.7 \% ; P=0.039$ ). After en bloc resection, five RNDL and three proximal lesions were judged R1/Rx at the $H M$. R1 resection at the HM was not observed in any lesion. When R0 resection could not be confirmed in RNDL specimens, the reason was $R 1 / R x$ within the squamous epithelium in two patients. In another two patients, non-neoplastic squamous epithelium was not found in the specimen while the margins showing R0 resection showed non-neoplastic rectal epithelium. In one patient, R1 was diagnosed within the rectal mucosa only. Recurrence rate was $1.2 \%(1 / 80)$ after en bloc resection and $66.7 \%(4 / 6)$ after piecemeal resection. Recurrences were small $(<5 \mathrm{~mm}$ in diameter) and were treated with forceps biopsy in four cases and with additional APC in one case. One patient with a small recurrence underwent surgery because of symptomatic stenosis of the proximal rectum.

\section{Complications}

Delayed bleeding occurred in five of 24 lesions (20.8\%) after ESD for RNDL and in none of the lesions that did not reach the dentate line $(P=0.001)$. In three patients, bleeding was treated with endoscopic clipping (Days 1, 2 and 12 after ESD). Coagulation of visible vessels was performed in the remaining two (Days 1 and 4). Blood transfusion was not required in any patient. None of the patients took anticoagulants at the time of the bleeding. Perforation was diagnosed during ER of a 50-mm LST $12 \mathrm{~cm}$ from the dentate line. Perforation was caused by snare resection when ESD had been switched to EMR because of poor maneuverability of the scope. An over-the-scope clip (OTSC, OVESCO, Tübingen, Germany) was used and antibiotics were administered. The further course was uneventful and the patient was discharged 48 hours later.

One patient developed rectal stenosis 2 months after ESD of a granular-type LST reaching the dentate line for $75 \%$ of the circumference, resulting in a resection ulcer of $90 \%$ of the circumference. Balloon dilatation was performed once and further follow-up over 10 months was uneventful. Another stenosis was diagnosed 2 months after circumferential ER of a recurrent LST after previous EMR. The lesion was located $12 \mathrm{~cm}$ from the anal verge and ESD had been switched to EMR because of severe submucosal fibrosis and poor maneuverability of the scope. After two sessions of balloon dilatation, recurrent adenoma was diagnosed within the stenosis 3 months after ER and the patient preferred surgical treatment. Transabdominal resection with temporary ileostomy was performed.

Antibiotics were administered in a prophylactic approach in 30 of 86 patients $(34.9 \%)$ ( $41.7 \%$ in the RNDL group versus $32.3 \%$ after ER of proximal lesions; $P=0.656$ ). Six of 56 patients $(10.7 \%)$ without prophylactic antibiotics developed fever $\left(>38^{\circ} \mathrm{C}\right.$ ) on the day of or after the procedure. Antibiotics were started when fever was observed and continued for 72 hours. Fever was seen also in three of 30 patients who had received prophylactic antibiotics $(10.0 \%)$. Temperature normalized within 48 hours in all patients.

Of the patients, $19.8 \%$ reported pain and accepted metamizole or acetaminophen within 48 hours after ER. Need for anal- 
- Table 1 Patient and lesion characteristics.

\begin{tabular}{|c|c|c|c|c|}
\hline & All lesions & $\begin{array}{l}\text { Lesion extending to } \\
\text { the dentate line }\end{array}$ & $\begin{array}{l}\text { Lesion distant from } \\
\text { the dentate line }\end{array}$ & $P$ \\
\hline N & 86 & 24 & 62 & \\
\hline Age, median (range), years & $64.0(41-84)$ & $68.5(41-83)$ & $63.0(45-84)$ & 0.258 \\
\hline $\begin{array}{l}\text { Sex, n (\%) } \\
\text { Male } \\
\text { Female }\end{array}$ & $\begin{array}{l}53(61.6 \%) \\
33(38.4)\end{array}$ & $\begin{array}{l}11(45.8) \\
13(54.2)\end{array}$ & $\begin{array}{l}42(67.7) \\
20(32.3)\end{array}$ & 0.104 \\
\hline ASA grade $1 / 2 / 3$ & $54 / 30 / 2$ & $12 / 11 / 1$ & $42 / 19 / 1$ & 0.287 \\
\hline Lesion size, median (range, $\mathrm{cm}^{2}$ ) & $\begin{array}{l}14.1 \\
(2.4-176.6)\end{array}$ & $\begin{array}{l}17.3 \\
(4.7-84.8)\end{array}$ & $\begin{array}{l}14.1 \\
(2.4-176.6)\end{array}$ & 0.658 \\
\hline $\begin{array}{l}\text { Treatment-naïve lesion } \\
\text { Pretreated lesion (previous EMR), n (\%) }\end{array}$ & $\begin{array}{l}72(83.7) \\
14(16.3)\end{array}$ & $\begin{array}{l}19(79.2) \\
5(20.8)\end{array}$ & $\begin{array}{l}53(85.5) \\
9(14.5)\end{array}$ & 0.522 \\
\hline $\begin{array}{l}\text { Lesion morphology } \\
\text { Paris classification } 0 \text {-Is/0-IIa/0-IIa +Is/0-IIa + lic } \\
\text { Surface pattern granular/ nongranular/mixed }\end{array}$ & $\begin{array}{l}5 / 17 / 63 / 1 \\
82 / 3 / 1\end{array}$ & $\begin{array}{l}1 / 4 / 19 / 0 \\
24 / 0 / 0\end{array}$ & $\begin{array}{l}4 / 13 / 46 / 1 \\
58 / 3 / 1\end{array}$ & $\begin{array}{l}0.860 \\
0.444\end{array}$ \\
\hline Histology LGIEN/HGIEN & $29 / 57$ & $12 / 12$ & $17 / 45$ & 0.083 \\
\hline
\end{tabular}

- Table 2 Procedure characteristics and recurrences.

\begin{tabular}{|c|c|c|c|c|}
\hline & All lesions & $\begin{array}{l}\text { Lesion extending to } \\
\text { the dentate line }\end{array}$ & $\begin{array}{l}\text { Lesion distant from } \\
\text { the dentate line }\end{array}$ & $P$ \\
\hline N & 86 & 24 & 62 & \\
\hline $\begin{array}{l}\text { Procedure time, } \\
\text { median (range), minutes }\end{array}$ & $\begin{array}{l}119 \\
(20-445)\end{array}$ & $\begin{array}{l}127 \\
(49-400)\end{array}$ & $\begin{array}{l}110 \\
(20-445)\end{array}$ & 0.182 \\
\hline Resection speed, median (range), minutes $/ \mathrm{cm}^{2}$ & $\begin{array}{l}6.9 \\
(2.0-20.4)\end{array}$ & $\begin{array}{l}7.1 \\
(3.6-19.4)\end{array}$ & $\begin{array}{l}6.6 \\
(2.0-20.4)\end{array}$ & 0.410 \\
\hline $\begin{array}{l}\text { Resection, } \mathrm{n}(\%) \\
\text { En bloc } \\
\text { Piecemeal }\end{array}$ & $\begin{array}{l}80(93.0) \\
6(7.0 \%)\end{array}$ & $\begin{array}{l}22(91.7 \%) \\
2(8.3 \%)\end{array}$ & $\begin{array}{l}58(93.5 \%) \\
4(6.5 \%)\end{array}$ & 0.670 \\
\hline $\begin{array}{l}\text { R0 resection, } n(\%) \\
\text { R0 } \\
\text { R1/Rx }\end{array}$ & $\begin{array}{l}72(83.7 \%) \\
14(16.3 \%)\end{array}$ & $\begin{array}{l}17(70.8 \%) \\
7(29.2 \%)\end{array}$ & $\begin{array}{l}55(88.7 \%) \\
7(11.3 \%)\end{array}$ & 0.039 \\
\hline $\begin{array}{l}\text { Recurrence, } \mathrm{n}(\%) \\
\text { After en bloc resection } \\
\text { After piecemeal resection }\end{array}$ & $\begin{array}{l}5(5.8 \%) \\
1(1.2 \%) \\
4(66.7 \%)\end{array}$ & $\begin{array}{l}2(8.3 \%) \\
1(4.5 \%) \\
1(50 \%)\end{array}$ & $\begin{array}{l}3(4.9 \%) \\
0 \\
3(75 \%)\end{array}$ & $\begin{array}{l}0.616 \\
0.275\end{array}$ \\
\hline
\end{tabular}

getics was higher in the RNDL group; because of small patient numbers, the difference was not statistically significant $(33.3 \%$ vs. $14.5 \%$; $P=0.07)$. At discharge, none of the patients needed further analgetics. Adverse events and their CTCAE grading are summarized in $>$ Table 3.

\section{Discussion}

Screening colonoscopies have been introduced in several countries over the last decades and could be shown to be effective in detecting premalignant adenomas and CRCs at an earlier stage. ER of benign adenomas prevents the incidence and reduces the mortality of colorectal cancer (CRC) [11]. However, ER becomes difficult and shows an increased risk of incomplete resection and recurrence when lesions are large $(\geq 40 \mathrm{~mm})$ or located close to the ileocecal valve, appendiceal orifice or dentate line [12]. For rectal neoplasia extending to the dentate line (RNDL), endoscopic resection techniques compete with transanal surgery. Randomized studies are lacking and the optimal treatment strategy is not well defined.

ER at the dentate line contains specific difficulties related to the anatomical features of the anal canal. In contrast to the proximal rectum scope, maneuverability is limited and visualization of the resection field is reduced. Moreover, risk for bleeding and pain might be increased due to presence of the rectal venous plexus and the sensory nerves in the squamous epithelium of the anal canal.

ESD can achieve high rates of en bloc resection and $\mathrm{R} 0$ resection regardless of lesion size, leading to minimization of risk of recurrence $[2,7]$. Another advantage is the possibility of inject- 
- Table 3 Complications of ESD in rectal neoplasia.

\begin{tabular}{|c|c|c|c|c|}
\hline & All lesions & $\begin{array}{l}\text { Lesion extending to } \\
\text { the dentate line }\end{array}$ & $\begin{array}{l}\text { Lesion distant from } \\
\text { the dentate line }\end{array}$ & $P$ \\
\hline $\mathrm{N}$ & 86 & 24 & 62 & \\
\hline $\begin{array}{l}\text { Delayed bleeding, } \mathrm{n}(\%) \\
\text { CTCAE grade }\end{array}$ & $5(5.8 \%)$ & $\begin{array}{l}5(20.8 \%) \\
2\end{array}$ & 0 & 0.001 \\
\hline $\begin{array}{l}\text { Perforation, n (\%) } \\
\text { CTCAE grade }\end{array}$ & $1(1.2 \%)$ & 0 & $\begin{array}{l}1(1.6 \%) \\
2\end{array}$ & 1.00 \\
\hline $\begin{array}{l}\text { Stenosis, } \mathrm{n}(\%) \\
\text { CTCAE grade }\end{array}$ & $2(2.4 \%)$ & $\begin{array}{l}1(4.2 \%) \\
2\end{array}$ & $\begin{array}{l}1(1.6 \%) \\
3\end{array}$ & 0.483 \\
\hline $\begin{array}{l}\text { Pain, } n(\%) \\
\text { CTCAE grade }\end{array}$ & 17 (19.8\%) & $\begin{array}{l}8(33.3 \%) \\
2\end{array}$ & $\begin{array}{l}9(14.5 \%) \\
2\end{array}$ & 0.07 \\
\hline $\begin{array}{l}\text { Use of prophylactic antibiotics, } n(\%) \\
\text { because of fever }\left(>38^{\circ} \mathrm{C}\right)\end{array}$ & $\begin{array}{l}30(34.9 \%) \\
6(7.0 \%)\end{array}$ & $\begin{array}{l}10(41.7 \%) \\
2(8.3 \%)\end{array}$ & $\begin{array}{l}20(32.3 \%) \\
4(6.5 \%)\end{array}$ & $\begin{array}{l}0.656 \\
0.479\end{array}$ \\
\hline Total & 36 (41.9\%) & $12(50 \%)$ & $24(38.7 \%)$ & \\
\hline
\end{tabular}

ing, cutting and coagulating very precisely and very close to the mucosa even in areas with poor maneuverability such as the anal canal. When ESD was not available, RNDL were treated surgically in most cases and only two small studies report exist on conventional EMR for such lesions. As reported from large EMR studies for colorectal neoplasia, these studies confirmed technical success with and safety of EMR but also a substantial recurrence risk of $22.2 \%$ and $18.4 \%$, respectively $[13,14]$. Holt et al. included 24 lesions involving the anorectal junction, which was defined as "involving the dentate line or lying within $2 \mathrm{~cm}$ of the dentate line" [13]. Liu et al included 49 lesions but only 24 of them showed a distance of less than $1 \mathrm{~cm}$ to the dentate line [14]. For interpretation of EMR data of RNDL, these inclusion criteria have to be taken into account and EMR might be even more difficult or impossible when involvement of the dentate line is extensive. Meanwhile, retrospective Asian studies reported on ESD for RNDL showing en bloc-resection rates exceeding $90 \%$ and a recurrence rate of $0 \%$ in most reports [1519]. Prospective data and Western data on ESD for RNDL are not available so far. Table 4 summarizes published studies on endoscopic treatment of RNDL.

In our study 86 patients with large rectal adenomas were treated with ESD. A substantial proportion (27.9\%) extended to the dentate line. Only lesions reaching the squamous epithelium were judged RNDL, which makes a comparison to published EMR data difficult.

As reported in nearly all studies on ER in RNDL and in contrast to studies including all colorectal neoplasia, a predominance of the female sex was seen in RNDL (54.2\%). In accordance with published data, we could confirm high en bloc resection for both RNDL and proximal rectal lesions (91.7\% vs. $93.5 \%, P=0.670)$. R0 resection was significantly lower after ESD for RNDL (70.8\% vs $88.7 \% ; P=0.039$ ). Despite the reduced R0 resection rate, the recurrence rate was low in the RNDL group and only one recurrence was observed after en bloc re- section of RNDL (4.5\%). A decreased R0 resection rate of only $53.3 \%$ after ESD for RNDL without an increase in the recurrence rate was also described by Imai et al. previously [16]. One reason might be thermal damage to the resection specimen at the distal margin within the squamous epithelium. This hypothesis is supported by findings from our study when $\mathrm{R} 1 / \mathrm{Rx}$ resection was located within the squamous epithelium in $80 \%$ and within the rectal mucosa in only $20 \%$. Due to the narrow space of the anal canal, a wide distance between the mucosal incision and the lesions margin cannot be achieved and risk for coagulation of lesion margins might be also increased during dissection. Close follow-up seems adequate after R1/Rx resection of ER in RNDL. Procedure time in our study was comparable with Asian data reporting median procedure times of 99 to 127 minutes [15-19].

Major concerns in ER close to the dentate line are risks for pain, bleeding, and bacteremia. In 2011, Sanchez-Yague et al. proposed injection of lidocaine to reduce intraprocedural and postprocedural pain [20]. Despite lack of data on the pain rate without injection of anesthetics and lack of further data, all Asian studies followed this regimen and reported postinterventional pain in $17.2 \%$ to $33.3 \%$ of cases. To avoid potential side effects after intravascular injection, we used injection fluid without local anesthetics in our study and observed pain in $33.3 \%$ of cases after ESD for RNDL but also in $14.5 \%$ after ESD distant from the dentate line. The theoretical benefit of local anesthetics is not well demonstrated today. It should be further investigated and a randomized study would be desirable. Asian authors report delayed bleeding in $0 \%$ to $28.6 \%$ of cases. We confirmed a significant increase in delayed bleeding after ESD of RNDL but endoscopic treatment was always possible $(20.8 \%$ vs. $0 \% ; P=0.001)$. The role of antibiotic prophylaxis to prevent fever and infection was unclear when we started our study. Imai et al. had reported a $22.2 \%$ rate of high-grade fever after ESD of RNDL but other authors did not report on this [16]. In our study, 
Table4 Published data on ER for RNDL.

\begin{tabular}{|c|c|c|c|c|c|c|c|c|}
\hline & $\begin{array}{l}\text { Holt et al. } \\
{[12]}\end{array}$ & $\begin{array}{l}\text { Liu et al. } \\
\text { [13] }\end{array}$ & $\begin{array}{l}\text { Nakadoi } \\
\text { et al. [14] }\end{array}$ & $\begin{array}{l}\text { Imai et al. } \\
\text { [15] }\end{array}$ & $\begin{array}{l}\text { Tamaru Y } \\
\text { et al. [16] }\end{array}$ & $\begin{array}{l}\text { Tanaka S, } \\
\text { et al. [17] }\end{array}$ & $\begin{array}{l}\text { Matsumoto } \\
\text { et al. [18] }\end{array}$ & $\begin{array}{l}\text { Probst et al. } \\
\text { (current) }\end{array}$ \\
\hline Study design & $\begin{array}{l}\text { non-ran- } \\
\text { domized } \\
\text { prospective }\end{array}$ & $\begin{array}{l}\text { non-ran- } \\
\text { domize } \\
\text { prospec- } \\
\text { tive }\end{array}$ & $\begin{array}{l}\text { non-ran- } \\
\text { domized } \\
\text { retrospec- } \\
\text { tive }\end{array}$ & $\begin{array}{l}\text { non-ran- } \\
\text { domized } \\
\text { retrospec- } \\
\text { tive }\end{array}$ & $\begin{array}{l}\text { non-ran- } \\
\text { domized } \\
\text { retrospec- } \\
\text { tive }\end{array}$ & $\begin{array}{l}\text { non-ran- } \\
\text { domized } \\
\text { retrospec- } \\
\text { tive }\end{array}$ & $\begin{array}{l}\text { non-ran- } \\
\text { domized } \\
\text { retrospec- } \\
\text { tive }\end{array}$ & $\begin{array}{l}\text { non-ran- } \\
\text { domized } \\
\text { prospective } \\
\text { data collec- } \\
\text { tion }\end{array}$ \\
\hline $\begin{array}{l}\text { Resection tech- } \\
\text { nique }\end{array}$ & EMR & EMR & ESD & ESD & ESD & ESD & ESD & ESD \\
\hline$n$ & $26^{1}$ & $49^{2}$ & $14^{3}$ & $45^{3}$ & $64^{3}$ & $71^{3}$ & $18^{3}$ & 24 \\
\hline Male & $53.8 \%$ & $57.1 \%$ & $28.6 \%$ & $33.3 \%$ & $43.7 \%$ & $36.6 \%$ & $50 \%$ & $45.8 \%$ \\
\hline $\begin{array}{l}\text { Lesions largest } \\
\text { diameter, mean } \\
\text { (range), mm }\end{array}$ & $40(25-180)$ & $\begin{array}{l}51 \\
(30-85)\end{array}$ & $\begin{array}{l}49 \\
(25-100)\end{array}$ & $38(9-80)$ & $\begin{array}{l}43 \\
(10-100)\end{array}$ & $52(6-158)$ & $\begin{array}{l}36 \\
\text { (range n.a.) }\end{array}$ & $55(30-120)$ \\
\hline En bloc resection & $\begin{array}{l}\text { N/A (piece- } \\
\text { meal) }\end{array}$ & $\begin{array}{l}\text { N/A (pie- } \\
\text { cemeal) }\end{array}$ & $85.7 \%$ & $95.6 \%$ & $93.8 \%$ & $98.6 \%$ & $100 \%$ & $91.7 \%$ \\
\hline R0 resection & $\begin{array}{l}\text { N/A (piece- } \\
\text { meal) }\end{array}$ & $\begin{array}{l}\text { N/A (pie- } \\
\text { cemeal) }\end{array}$ & $\mathrm{N} / \mathrm{A}$ & $53.3 \%$ & $93.8 \%$ & $\mathrm{~N} / \mathrm{A}$ & $88.9 \%$ & $70.8 \%$ \\
\hline $\begin{array}{l}\text { Procedure time, } \\
\text { mean (range), } \\
\text { minutes }\end{array}$ & $26(5-80)$ & $\begin{array}{l}57 \\
(29-126)\end{array}$ & $\begin{array}{l}99 \\
(30-240)\end{array}$ & $\begin{array}{l}104 \\
(25-420)\end{array}$ & $\begin{array}{l}121 \\
(30-270)\end{array}$ & $\begin{array}{l}127 \\
(28-540)\end{array}$ & $\begin{array}{l}103 \\
\text { (range n.a.) }\end{array}$ & $\begin{array}{l}127 \\
(49-400)\end{array}$ \\
\hline $\begin{array}{l}\text { Injection of anes- } \\
\text { thetic }\end{array}$ & $\begin{array}{l}\text { ropivacaine } \\
\text { or bupiva- } \\
\text { caine } 0.5 \%\end{array}$ & none & $\begin{array}{l}\text { lidocaine } \\
1 \%\end{array}$ & $\begin{array}{l}\text { lidocaine } \\
1 \%\end{array}$ & $\begin{array}{l}\text { lidocaine } \\
1 \%\end{array}$ & $\begin{array}{l}\text { lidocaine } \\
1 \%\end{array}$ & $\begin{array}{l}\text { lidocaine } \\
1 \%\end{array}$ & none \\
\hline $\begin{array}{l}\text { Delayed bleeding } \\
\text { Perforation } \\
\text { Stenosis } \\
\text { Pain }\end{array}$ & $\begin{array}{l}4.2 \% \\
0 \\
8.3 \% \\
\text { n.a. }\end{array}$ & $\begin{array}{l}8.2 \% \\
0 \\
0 \\
\text { n.a. }\end{array}$ & $\begin{array}{l}28.6 \% \\
0 \\
7.1 \% \\
7.1 \%\end{array}$ & $\begin{array}{l}2.2 \% \\
4.4 \% \\
2.2 \% \\
26.7 \%\end{array}$ & $\begin{array}{l}14 \% \\
0 \\
1.6 \% \\
17.2 \%\end{array}$ & $\begin{array}{l}0 \\
0 \\
\text { n.a. } \\
\text { n.a. }\end{array}$ & $\begin{array}{l}5.6 \% \\
0 \\
\text { n.a. } \\
33.3 \%\end{array}$ & $\begin{array}{l}20.8 \% \\
0 \\
4.2 \% \\
33.3 \%\end{array}$ \\
\hline Recurrence & $22.2 \%$ & $18.4 \%$ & 0 & 0 & 0 & 0 & $N / A$ & $4.5 \%$ \\
\hline \multicolumn{9}{|c|}{$\begin{array}{l}\text { N/A, not available } \\
1 \text { Lesions involved the dentate line or were lying within } 2 \mathrm{~cm} \text { of the dentate line } \\
224 \text { lesions }(49 \% \text { ) were located } 0 \text { to } 1.0 \mathrm{~cm} \text { from the dentate while } 25(51 \%) \text { were located } 1.1 \text { to } 2.0 \mathrm{~cm} \text { from the dentate line } \\
{ }^{3} \text { All lesions involved the dentate line }\end{array}$} \\
\hline
\end{tabular}

antibiotics were administered individually depending on the endoscopist's decision. High-grade fever occurred in $10.6 \%$ of patients who had received prophylactic antibiotics and in $10 \%$ of patients who had not received the drugs. Severe infections were not observed. Due to non-randomization we cannot draw a conclusion from these observations. Recently, Lee et al. demonstrated a significant reduction in post-ESD electrocoagulation syndrome after use of prophylactic antibiotics in a randomized study [21]. In accordance with these data, we would recommend prophylactic antibiotics for all colorectal ESDs in the future.

ER of RNDL competes with surgical resection techniques such as transanal full-thickness-resection and transanal endoscopic microsurgery (TEM). Recently, a randomized study failed to demonstrate non-inferiority of conventional EMR in comparison to TEM. Recurrence rates were $15 \%$ after EMR and $11 \%$ after TEM. Median procedure times were 53 minutes and 60 minutes, respectively. Specific analysis of RNDL was not includ- ed [22]. Randomized prospective studies comparing ESD and surgery are lacking.

\section{Conclusions}

ESD is a feasible and safe resection technique for RNDL. The recurrence rate is lower than that previously reported for EMR and TEM. Rates of delayed bleeding and postinterventional pain are increased in RNDL but complications can be managed conservatively.

Limitations of this study are the small number of patients and lack of a control group. Randomized controlled trials comparing ESD to other resection techniques (EMR or transanal surgery) are needed to define the ideal treatment strategy for RNDL. 
Competing interests

None

\section{References}

[1] Moss A, Williams S], Hourigan LF et al. Long-term adenoma recurrence following wide-field endoscopic mucosal resection (WF-EMR) for advanced colonic mucosal neoplasia is infrequent: results and risk factors in 1000 cases from the Australian Colonic EMR (ACE) study. Gut 2015; 64: 57-65

[2] Saito Y, Fukuzawa M, Matsuda T et al. Clinical outcome of endoscopic submucosal dissection versus endoscopic mucosal resection of large colorectal tumors determined by curative resection. Surg Endosc 2010; 24: $343-352$

[3] Probst A, Golger D, Arnholdt $\mathrm{H}$ et al. Endoscopic submucosal dissection of early cancers, flat adenomas and submucosal tumors in the gastrointestinal tract. Clin Gastroenterol Hepatol 2009; 7: 149-155

[4] Probst A, Golger D, Anthuber M et al. Endoscopic submucosal dissection of large sessile lesions of the rectosigmoid: learning curve in a European center. Endoscopy 2012; 44: 660-667

[5] Pimentel-Nunes P, Dinis-Ribeiro M, Ponchon T et al. Endoscopic Submucosal Dissection: European Society of Gastrointestinal Endoscopy (ESGE) Guideline. Endoscopy 2015; 47: 829-854

[6] Rutter MD, Chattree A, Barbour JA et al. British Society of Gastroenterology/Association of Coloproctologists of Great Britain and Ireland guidelines for the management of large non-pedunculated colorectal polyps. Gut 2015; 64: $1847-1873$

[7] Probst A, Ebigbo A, Märkl B et al. Endoscopic submucosal dissection for early rectal neoplasia: experience from a European center. Endoscopy 2017; 49: $222-232$

[8] Endoscopic ClassificationReview Group. Update on the Paris Classification of Superficial Neoplastic Lesions in the Digestive Tract. Endoscopy 2005; 37: $570-578$

[9] Kudo S, Lambert R, Allen JI et al. Nonpolypoid neoplastic lesions of the colorectal mucosa. Gastrointest Endosc 2008; 68: S3-S47

[10] Cotton PB, Eisen GM, Aabakken L et al. A lexicon for endoscopic adverse events: report of an ASGE workshop. Gastrointest Endosc 2010; 71: $446-454$
[11] Zauber AG, Winawer SJ, O’Brien M] et al. Colonoscopy polypectomy and long-term prevention of colorectal-cancer deaths. N Engl J Med 2012; 366: 687-696

[12] Rutter MD, Chattree A, Barbour JA et al. British Society of Gastroenterology/Association of Coloproctologists of Great Britain and Ireland guidelines for the management of large non-pedunculated colorectal polyps. Gut 2015; 64: $1847-1873$

[13] Holt BA, Bassan MS, Sexton A et al. Advanced mucosal neoplasia of the anorectal junction: endoscopic resection technique and outcomes (with videos). Gastrointest Endosc 2014; 79: 119-126

[14] Liu S, Li Y, Yang H et al. Retroflexion-assisted endoscopic mucosal resection: a useful and safe method for removal of low rectal laterally spreading tumors. Surg Endosc 2016; 30: 139-146

[15] Nakadoi K, Tanaka S, Hayashi N et al. Clinical outcomes of endoscopic submucosal dissection for rectal tumor close to the dentate line. Gastrointest Endosc 2012; 76: 444-450

[16] Imai K, Hotta K, Yamaguchi Y et al. Safety and efficacy of endoscopic submucosal dissection of rectal tumors extending to the dentate line. Endoscopy 2015; 47: 529-532

[17] Tamaru Y, Oka S, Tanaka S et al. Endoscopic submucosal dissection for anorectal tumor with hemorrhoids close to the dentate line: a multicenter study of Hiroshima GI Endoscopy Study Group. Surg Endosc 2016; 30: 4425-4431

[18] Tanaka S, Toyonaga T, Morita Y et al. Feasibility and safety of endoscopic submucosal dissection for lower rectal tumors with hemorrhoids. World J Gastroenterol 2016; 22: 6268-6275

[19] Matsumoto S, Mashima H. The efficacy of endoscopic submucosal dissection for colorectal tumors extending to the dentate line. Int J Colorectal Dis 2017; 32: 831-837

[20] Sanchez-Yague A, Yamaguchi Y, Takao T et al. Endoscopic submucosal dissection of a lower rectal polyp proximal to the dentate line by using local lidocaine injection. Gastrointest Endosc 2011; 73: 405-407

[21] Lee SP, Sung IK, Kim JH et al. A randomized controlled trial of prophylactic antibiotics in the prevention of electrocoagulation syndrome after colorectal endoscopic submucosal dissection. Gastrointest Endosc 2017; 86: 349-357

[22] Barendse RM, Musters GD, de Graaf EJR et al. Randomised controlled trial of transanal endoscopic microsurgery versus endoscopic mucosal resection for large rectal adenomas (TREND Study). Gut 2017; 67: $837-846$ 